\title{
Spatial variability in floodplain sedimentation: the use of generalized linear mixed-effects models
}

\author{
A. Cabezas ${ }^{1,2}$, M. Angulo-Martínez ${ }^{3}$, M. Gonzalez-Sanchís ${ }^{1}$, J. J. Jimenez ${ }^{1}$, and F. A. Comín ${ }^{1}$ \\ ${ }^{1}$ Pyrenean Institute of Ecology-Spanish Research Council, IPE-CSIC. 1005 Avd. Montañana, 50080 Zaragoza, Spain \\ ${ }^{2}$ Leibniz-Institute of Freshwater Ecology and Inland Fisheries, IGB, Müggelseedamm 301, 12587 Berlin, Germany \\ ${ }^{3}$ Aula Dei Experimental Station - Spanish Research Council, EEAD-CSIC. 1005 Avda. Montañana, 50080 Zaragoza, Spain
}

Received: 10 February 2010 - Published in Hydrol. Earth Syst. Sci. Discuss.: 26 February 2010

Revised: 2 August 2010 - Accepted: 12 August 2010 - Published: 25 August 2010

\begin{abstract}
Sediment, Total Organic Carbon (TOC) and total nitrogen (TN) accumulation during one overbank flood (1.15y return interval) were examined at one reach of the Middle Ebro River (NE Spain) for elucidating spatial patterns. To achieve this goal, four areas with different geomorphological features and located within the study reach were examined by using artificial grass mats. Within each area, $1 \mathrm{~m}^{2}$ study plots consisting of three pseudo-replicates were placed in a semi-regular grid oriented perpendicular to the main channel. TOC, TN and Particle-Size composition of deposited sediments were examined and accumulation rates estimated. Generalized linear mixed-effects models were used to analyze sedimentation patterns in order to handle clustered sampling units, specific-site effects and spatial self-correlation between observations. Our results confirm the importance of channel-floodplain morphology and site micro-topography in explaining sediment, TOC and TN deposition patterns, although the importance of other factors as vegetation pattern should be included in further studies to explain small-scale variability. Generalized linear mixedeffect models provide a good framework to deal with the high spatial heterogeneity of this phenomenon at different spatial scales, and should be further investigated in order to explore its validity when examining the importance of factors such as flood magnitude or suspended sediment concentration.
\end{abstract}

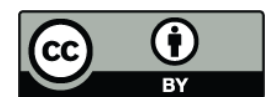

Correspondence to: A. Cabezas (acabezas@ymail.com)

\section{Introduction}

Riverine floodplains can buffer the transport of sediment as washload mobilised from the upstream parts of the catchment. Such sediment deposition over floodplains is an important process in the storage and cycling of sediments, nutrients and contaminants in the river basins (Walling et al., 1997; Steiger and Gurnell, 2003; Walling and Owens, 2003; Noe and Hupp, 2009). Focussing on organic carbon (TOC) and nitrogen (TN), deposition during overbank floods is an important ecosystem function which provides important benefits as water quality enhancement or mitigation of greenhouse effect (Johnston, 1991; Day et al., 2004; Verhoeven et al., 2006, IPCC, 2007). At the reach scale, TOC and TN exchange between the main channel and its adjacent floodplain plays a key role in the ecological functioning (Junk, 1999; Robertson et al., 1999; Tockner et al., 1999; Tockner at al., 2000; Thoms, 2003; Knosche, 2006; Preiner et al., 2008). Previous research has shown how human-induced changes at the basin and reach scale have decreased the potential of riverine floodplains to act as sediment-associated nutrient sinks (Noe and Hupp, 2005; Owens et al., 2005; Pierce and King, 2008; Cabezas et al., 2009; Cabezas and Comin, 2010). To accomplish knowledge-based management and restoration strategies at specific river reaches, TOC and TN deposition patterns must be properly understood.

The amounts and patterns of overbank sedimentation depend on several factors, namely frequency and duration of inundation, suspended sediment concentration in the main channel, and the flow patterns and stream velocity during floods. Regarding individual events, hydraulic connectivity determines the loading rate of material over floodplains. Hydraulic connectivity, in turn, is controlled at the reach

Published by Copernicus Publications on behalf of the European Geosciences Union. 
scale by channel-floodplain geomorphology, which promotes spatial variability on sedimentation load and patterns for a given river section during a specific flood event (Hupp, 2000; Steiger and Gurnell, 2003; Noe and Hupp, 2005; Piégay et al., 2008). At this scale, previous studies have indicated that distance from the main channel exerts more influence on spatial variability of overbank sedimentation than downstream variation (Walling and He, 1998; Middelkoop and Asselman, 1998; Thonon et al., 2007). Such trends were also observed at specific floodplain sections - site-scale - with uniform relief. At more complex sites, however, heterogeneity was strongly related with site micro-topography since it controls flow hydraulics, and thus suspended sediment transport and deposition (Nicholas and Walling, 1997; Hupp et al., 2009). With regards to TOC and TN, the amount of sediment deposited and particle-size composition seem to determine the TOC and TN deposited in situ during overbank floods (Asselman and Middelkoop, 1995; Walling and He, 1997; Steiger and Gurnell, 2003).

In this context, different modelling approaches have been employed to predict sedimentation processes and flood effects. Earlier numerical modelling research focussed on diffusive sediment and grain-size deposition across channel and floodplain sections (James, 1985; Pizzuto, 1987). By coupling hydraulic and sediment deposition models, field-based sedimentation rates and digital elevation models of the floodplain surface were incorporated to numerical modelling in order to reflect the high spatial heterogeneity observed in field-based investigations. Some of these models are based on a discrete-element approach (Stewart et al., 1998; Buttner et al., 2006), and other models on a finite-element approach (Nicholas and Walling, 1997; Nicholas and Walling, 1998; Middelkoop and Van der Perk, 1998). Those techniques advanced the potential to predict sedimentation effects by simple, computationally efficient functions parameterised by distance from the main channel and floodplain elevation. It also allows the inclusion of the effect of the meso-scale topographic features as abandoned channels, levees or drainage ditches (Nicholas and Mitchell, 2003).

However, empirical studies on contemporary sediment deposition are still needed to gain insight into the key variables that determine spatial heterogeneity (Walling et al., 2004). Despite the complexity of floodplain sedimentation, individual studies rarely incorporate a multi-scale approach when analysing data, although variability at different spatial scales is described and the factors promoting such variability identified. Previous studies have reported high heterogeneity on floodplain sedimentation (reach scale) when comparing sites located within the same study reach (Middlekoop and Asselman, 1998; Walling and He, 1997; Steiger and Gurnell, 2003). Within each site, self-correlation between observation points was observed (site scale). Moreover, self-correlation patterns greatly differed between study sites within the same reach (Middlekoop and Asselman, 1998; Nicholas and Walling, 2003). With regards to smaller scales, the plot scale variability $\left(\sim 1 \mathrm{~m}^{2}\right)$ is normally taken into account during the experimental design although not often included in statistical analyses or spatial interpolation (Middelkoop and Asselman, 1998; Steiger and Gurnell, 2003; Steiger et al, 2003).

In the current paper, we aimed to investigate sediment, TOC and TN deposition patterns during one individual flood by considering variability at the reach, site and plot scales. To fulfil our goal, generalized linear mixed-effect models (GLME) represent a potentially useful tool. GLME combine the properties of two statistical frameworks (Bolker et al., 2009): (a) Linear mixed models, which incorporate the effect of random effects; (b) Generalized linear models, which handle nonnormal data by using link functions and the exponential family (Poisson, normal, binomial) distributions. By using GLME, hierarchical-data analysis can be performed. GLME represent a class of regression models which do not assume that all observations are independent from each other, and so can be used to analyze data from clustered experimental designs where observed subjects are nested within larger units. By doing so, cluster-specific random effects and correlated residual structures are included in the analyses (Pinheiro and Bates, 2000; Heegaard and Nilsen, 2007). Thus, GLME are able to account for differences between floodplain sections when evaluating floodplain sedimentation in a given reach (reach scale). Self-correlation between observation points lying within the same section (site scale) can be also taken into account by using GLME (Witherington et al., 2009), whereas the small-scale variability (plot scale) is considered without averaging the data. The validity of GLME as a tool to investigate spatial variability in floodplain sedimentation studies is also discussed.

\section{Materials and methods}

\subsection{Study reach}

The study reach (Fig. 1) is located in the Middle Ebro River (NE Spain), which is the largest river in Spain - watershed area $=85362 \mathrm{~km}^{2}$; river length $=910 \mathrm{~km}$; average discharge to the Mediterranean Sea $=14442 \times 10^{6} \mathrm{~m}^{3} \mathrm{y}^{-1}$ (1927-2007). Within this section, the average floodplain width is about $5 \mathrm{~km}$ (Ollero, 1995). The main channel has a wandering morphology - sinuosity $=1.39$; mean channel slope $=0.050 \%$; mean channel width $=110.31 \pm 36.3 \mathrm{~m}$ - with elongated meanders and scarcity of in-channel islands. Within the reach studied, the daily average discharge is $228.24 \mathrm{~m}^{3} / \mathrm{s}-1927-2007$ - and the elevation ranges between $175 \mathrm{~m}$ a.s.l. in the river channel to $185 \mathrm{~m}$ a.s.l. at the base of the scarp. At the Zaragoza city gauging station - A011 at www.chebro.es, $12 \mathrm{~km}$ upstream the study reach - the potential storage capacity is $163719 \mathrm{hm}^{3}$, impounding about $50 \%$ of the mean annual runoff. Regarding to landscape composition, agricultural fields have increasingly 


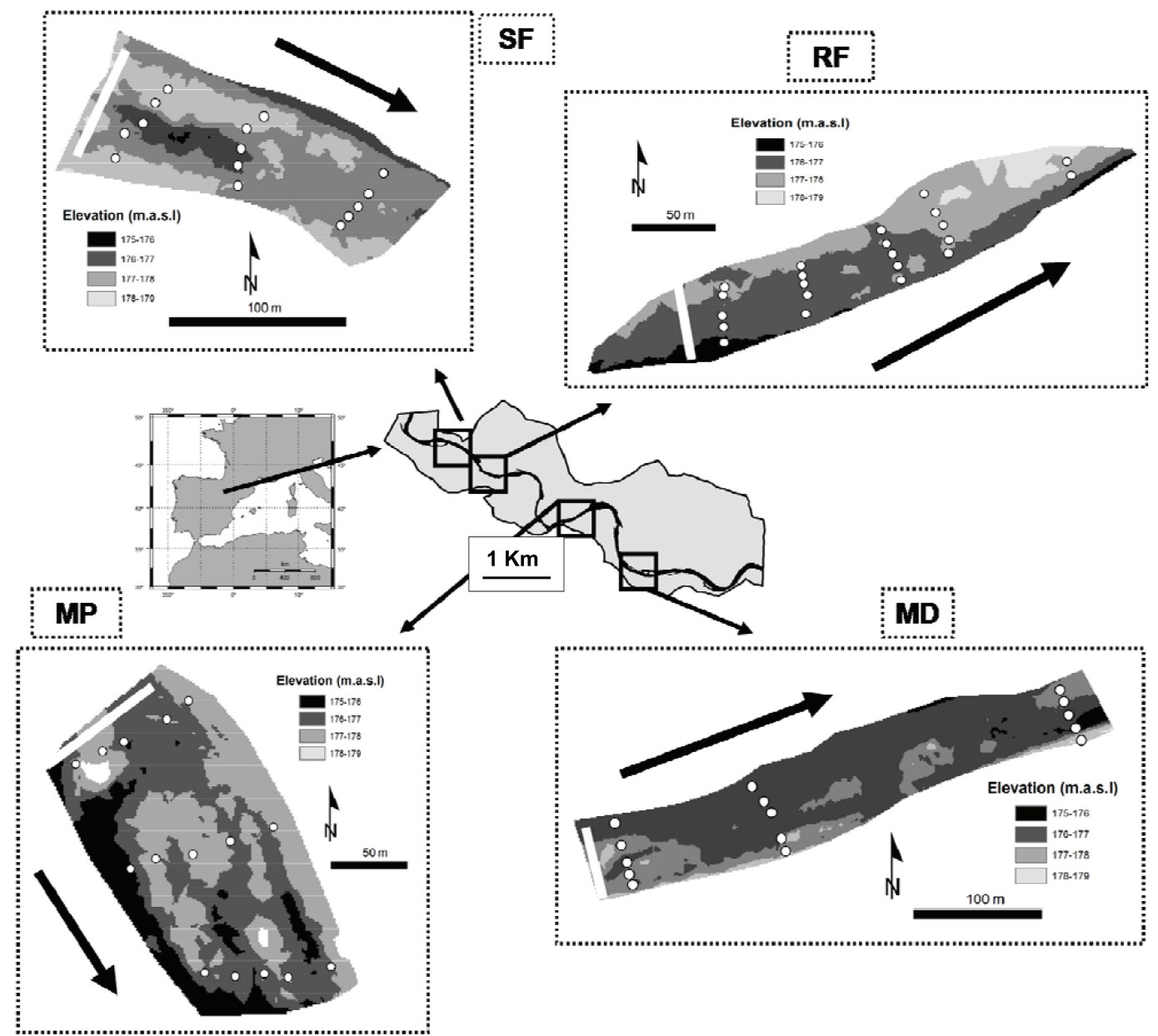

Fig. 1. Location of study plots along the four sites selected within the study reach, which are represented by a detailed Digital Elevation Model. Black arrows indicate the direction of the Ebro River flow. White circles represent the location of the study plots, reflecting an incremental distance to main channel along a perpendicular gradient. White solid lines at each site represent the area where surface water inputs the site, which has been the reference to calculate distances along a longitudinal gradient (see methods).

Table 1. Description of sites where study plots were set.

\begin{tabular}{lllcl}
\hline Site & $\begin{array}{l}\text { Geomorphological } \\
\text { feature }\end{array}$ & $\begin{array}{l}\text { Planform setting } \\
\text { of channel bank }\end{array}$ & $\begin{array}{c}\text { Surface } \\
\text { connectivity } \\
\left(\mathrm{m}^{3} / \mathrm{s}\right)\end{array}$ & $\begin{array}{l}\text { Dominant } \\
\text { land-cover }\end{array}$ \\
\hline MP & Point Bar & convex & 350 & Gravel and shrubs \\
MD & Side Channel & concave, natural levee & 400 & Water, grass and trees \\
SF & Side Channel & convex, natural levee & 800 & Water, grass and trees \\
RF & Bench & convex & 600 & Grass and shrubs \\
\hline
\end{tabular}

dominated over natural patch types since 1957, and lateral migration of the main channel has not occurred since 1981 (Cabezas et al., 2009).

\subsection{Sediment sampling and analyses}

Sediment traps were used to collect the sediment deposited by a 27 days-duration flood on March 2007 (Fig. 2), which reached $162 \mathrm{~m}^{3} / \mathrm{s}-1.15 \mathrm{y}$ return interval, 1927-2003; $2.73 \mathrm{y}$ return interval, 1981-2003 - at the Zaragoza gauge station - A011 in www.chebro.es; $12 \mathrm{~km}$ upstream from the study area. The sediment traps were placed in four sites with different geomorphological traits and channel-floodplain connectivity - Fig. 1, Table 1: Mejana de Pastriz (MP) and Margen Derecha (MD), with higher channel-floodplain connectivity 


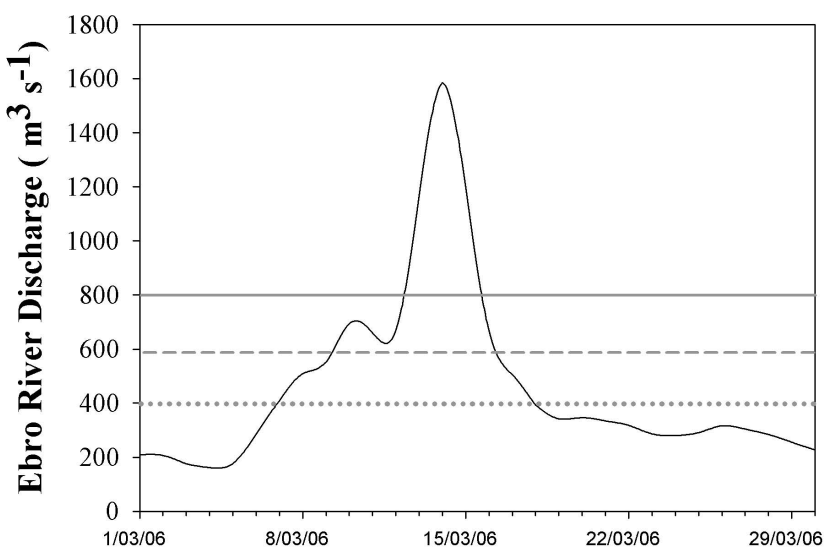

Fig. 2. Ebro River daily average discharge at the Zaragoza city gauge station during the examined flood. Dot grey line indicates the surface connectivity threshold for MP and MD. Dash grey line indicates the surface connectivity threshold RF. Solid grey line indicates the surface connectivity threshold for SF.

than Soto del Francés (SF) and Rincón Falso (RF). Each area was completely inundated during the examined flood. At each area, $1 \mathrm{~m}^{2}$ plots $-\mathrm{p}=15$ at MP, MD and SF; $\mathrm{p}=22$ at RF were placed in a semi-regular grid, consisting of several transects $-\mathrm{t}=3$ at MP, MD and $\mathrm{SF} ; \mathrm{t}=5$ at $\mathrm{RF}-$ that were oriented perpendicular to the main stream (Fig. 3). The shape and size of each area directed the space between transects and between plots. Study plots were marked by burying a metallic stick, which was geo-referenced using a differential GPS device - Top-Com, $\pm 2 \mathrm{~cm}$. In each plot, three $25 \times 25 \mathrm{~cm}$ sediment traps - pseudo-replicates - made of artificial grass mats $-i=201-$ which had been previously weighed, were affixed to the surface using $14 \mathrm{~cm}$ steel pins. Pseudo-replicates were placed at $30 \mathrm{~cm}$ on the left, right and opposite-to-theriver side of the metallic sticks. Sediment traps were set during the second and third week of February 2006. For each pseudo-replicate, three geographical variables were considered: (i) elevation above sea level $(\mathrm{m})$, extracted from the GPS device measurements; (ii) perpendicular distance (m) to the main channel; and (iii) longitudinal distance, calculated as the distance to the zone where superficial inputs enters during overbank floods (Fig. 1), which is located at the upstream part of each site $(j=4)$ and was previously identified from field-based knowledge. Both perpendicular and longitudinal distances were estimated using ArcGIS 9.2

A few days after the flood event, when all of the mats had re-emerged, they were taken to the lab and air-dried at lab temperature during three weeks. Only $3.99 \%$ of the artificial grass mats were flushed away by the river. Sedimentation rates were calculated as sediment dry mass per area unit $\left(\mathrm{kg} / \mathrm{m}^{2}\right)$ after re-weighing each sediment trap, which had been weighed prior installation. Afterwards, a sediment sample was removed from each trap by hand using a brush with metallic bristles. To ensure homogeneity, mats were brushed from the centre to the edge covering one quarter. After that, samples were gently mixed by hand. At plots presenting low sedimentation, mats presented great heterogeneity. In these cases, the entire mat was brushed to ensure homogeneity and get enough sediment for further analyses. All sediment samples were finer than $2 \mathrm{~mm}$, so sieving was necessary. Coarse particulate organic matter $(>2 \mathrm{~mm})$ was very rare and removed when present. An aliquot was separated for particlesize analysis with a laser-diffraction instrument (Coulter LS 230, Beckman Coulter). The $<4 \mu \mathrm{m},<63 \mu \mathrm{m},<125 \mu \mathrm{m}$, $<250 \mu \mathrm{m}$ and $<500 \mu \mathrm{m}$ particle-size separates were considered for further analyses. These fractions cumulatively represent the clay, silt, and very fine sand, fine sand and medium sand fractions according to Weinthwork (1922). The sediment samples were ground with a mortar and pestle prior to measure Total Organic Carbon (TOC) and Total Nitrogen (TN) using elemental analysis (Leco SC-144DR and Elementar Variomax CN, respectively). Details on TOC determination can be found in Cabezas et al. (2009b). TOC $\left(\mathrm{g} \mathrm{C} \mathrm{m}^{-2}\right)$ and $\mathrm{TN}\left(\mathrm{g} \mathrm{N} \mathrm{m}^{-2}\right)$ accretion rates were calculated multiplying by sedimentation rates.

\subsection{Spatial heterogeneity at the reach scale}

To describe spatial variability at the reach scale, inter-site $(j=4)$ differences on $\operatorname{TOC}\left(\%, \mathrm{~g} \mathrm{C} \mathrm{m}^{-2}\right), \mathrm{TN}\left(\%, \mathrm{~g} \mathrm{~N} \mathrm{~m}^{-2}\right)$, particle size-class separates $(\%<4,63,125,250,500 \mu \mathrm{m})$ and sedimentation rates $\left(\mathrm{kg} \mathrm{m}^{-2}\right)$ were explored. After ensuring that data met the assumption of normality (including transformations where appropriate), a one-way ANOVA was performed using SPSS 14.0. Depending on the homogeneity of the variance, either SNK or Tahmane Tests were used in post-hoc comparisons.

The existence of spatial self-correlation was tested for the three variables by finding the most appropriate semivariogram models to fit the empirical semi-variograms computed from the samples. The $\mathrm{R}$ statistical analysis system - function variogram in the spatial library - (R Development Core Team, 2008) was used in the calculations. Spatial self-correlation was assumed isotropic, since it is one of the main assumptions when including spatial correlation in the GLME models (Pinheiro and Bates, 2000). The Akaike Information Criterion (AIC - Sakamoto, Ishiguro and Kitagawa, 1986) was used for finding the best semi-variogram model. A Gaussian semi-variogram model was choosen for the sedimentation rate, whereas an Exponential semivariogram model was applied to TOC and TN deposition.

\subsection{Spatial heterogeneity at decreasing spatial scale: site, transect, row and plot}

For each study site, ranges of values (maximum - minimum) of TOC $\left(\%, \mathrm{~g} \mathrm{C} \mathrm{m}^{-2}\right)$, TN $\left(\%, \mathrm{~g} \mathrm{~N} \mathrm{~m}^{-2}\right)$ and sedimentation rates $\left(\mathrm{kg} \mathrm{m}^{-2}\right)$ were calculated for the plot, transect, row and site scales in order to describe spatial variability within study 


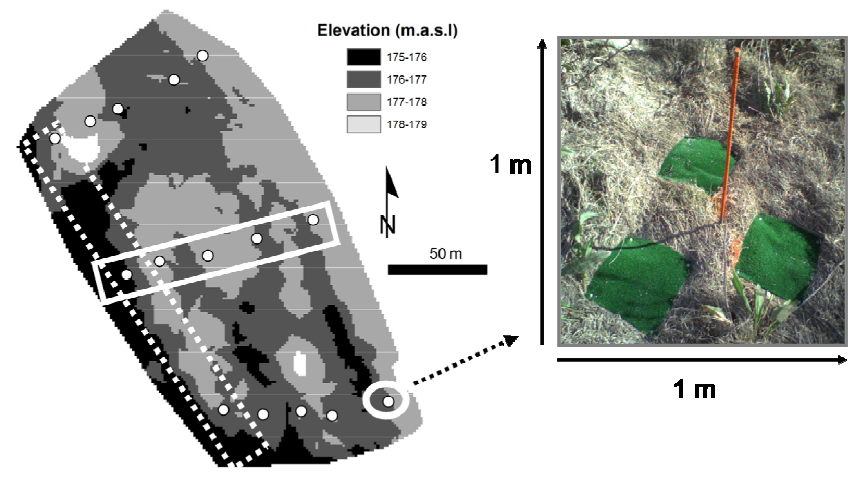

Fig. 3. Representation of the different spatial scales considered in one of the examined areas (MP, see Fig. 1). The biggest one, the study site scale, encounters the area containing all study plots within a site. The solid rectangle is an example of the area encountered by transects spatial scale, which represents the gradient perpendicular to the main channel. The dashed rectangle is an example of the area encountered by the row spatial scale, which represents the gradient parallel to the main channel. The displayed picture shows the composition of one study plot (solid circle).

sites (Fig. 3). The plot scale represented $1 \mathrm{~m}^{2}$ portions of each study site (3 pseudo-replicates). The transect and row scales (Fig. 3) were selected to assess the spatial variation of sediment deposition in the direction parallel and perpendicular to the river. As first pointed by Burrough (1996), this anisotropy on spatial variability is often encountered on river systems. The site scale showed spatial variability within sites $-j=4-$ with different geomorphological traits. Areas represented by each transect, row and site were identified in the field according to geomorphological traits. Afterwards, the areas were delimitated over 2003 ortho-images using ArcMap 9.2 with a fixed scale of 1:3000, and calculated using the XTools application. Ranges of values at each scale were calculated taking into account sediment traps enclosed at each of the different spatial scales.

Moreover, two different aspects on the relationship between quantity and composition of deposited sediment were evaluated for each site: (i) influence of particle-size separates over TOC (\%) and TN (\%) concentrations; (ii) Influence of particle-size separates over sediment $\left(\mathrm{kg} \mathrm{m}^{-2}\right)$, TOC $\left(\mathrm{g} \mathrm{C}^{-2}\right)$ and $\mathrm{TN}\left(\mathrm{g} \mathrm{N} \mathrm{m}^{-2}\right)$ deposition rates. To accomplish that, Pearson correlations were performed using SPSS.

\subsection{Evaluation of the spatial variability at the reach scale using GLME modelling}

Spatial variability of sediment rate, TOC and TN was assessed at the reach scale using generalized linear mixedeffects (GLME) models. Unlike standard linear models, mixed-effects models allow incorporating both fixed-effects and random-effects in the regression analysis (Pinheiro and Bates, 2000). The fixed-effects in a model describe the val- ues of the response variables in terms of explanatory variables that are considered to be non-random, whereas the random-effects are treated as arising from random causes. Random effects can be associated with the individual experimental units sampled from the population, hence mixedeffects models are particularly suited to experimental settings where measurements are made on groups of related experimental units. If the classification factor is ignored when modelling grouped data, the random (group) effects are incorporated in the residuals, leading to an inflated estimate of the within-site variability.

In our case, relationships were explored between the response variables - Sedrate, TOC and TN - and the covariates - longitudinal and transverse distance to the main channel and percentages of deposited particle size - on a data set grouped according to one classification factor with four levels - the four sampling sites: MP, MD, RF and SF . Hence, the mixed-effects model allows for the identification of relationships between the response variables and the covariates that are general to the four sites, irrespective of the local differences between the sites, which are considered a random effect.

The mixed-effects model combines a random-effects analysis of variance model with a linear regression model. The mathematical formulation takes the form:

$y_{j i}=\beta_{1}+b_{j}+\beta_{2} x_{j i}+\varepsilon_{j i} j=1, \ldots, 4 ; i=1, \ldots, 201$

Where $y_{j i}$ is the ith observation in the jth group of data and $x_{j i}$ is the corresponding value of the covariate, an analysis of covariance with a random effect for the intercept; $\beta_{1}$ is the mean variable value across the population being sampled, $b_{j}$ is a random variable representing the deviation from the population mean of the mean variable value for the jth intersite study area, and $\epsilon_{j i}$ is a random variable representing the deviation in the mean variable value for observation $i$ on $j$ from the mean variable value for $j$ on $i$.

To complete the statistical model, we must specify the distribution of the random variables $b_{j}, j=1, \ldots, 4$ and $\epsilon_{j i}$, $j=1, \ldots, 4 ; i=1, \ldots, 201$. We begin by modelling both of these as independent, normally distributed random variables with mean zero and constant variance. The variances are denoted $\sigma_{b}^{2} b_{j}$, or between site variability, and $\sigma^{2}$ for the $\epsilon_{j i}$, or within-site variability. This is expressed as:

$b_{j}, \sim N\left(0, \sigma_{b}^{2}\right), \epsilon_{j i} \sim N\left(0, \sigma^{2}\right)$

Generalized linear mixed-effects (GLME) models allow including a correlation structure to model the spatial dependence between observations. The inclusion of spatial correlation can be achieved by decomposing the within-group variance-covariance structure $-\epsilon_{j i}$ - into a product of simpler matrices: (i) one describing the variance structure of the within-group errors, (ii) and the other matrix describing the correlation structure of the within-group errors. The spatial correlation is represented by its semi-variogram; the type 
of correlation function used to model spatial dependence for Sedrate, TOC and TN corresponds with the best adjustment achieved when modelling their semi-variogram.

The within-group variance-covariance structure $-\epsilon_{j i}-$ in any model can be assumed to have a homoscedastic withingroup error structure, which mean that all within-groups errors assume the same variance. A more general model allows for different variances between study areas and between plots within a study area (heterocedasticity). Heterocedasticity can be included in GLME models by means of a variance function. Heteroscesdasticity was evaluated for all three variables - Sedrate, TOC and TN. Several methods exist for fitting GLME models, including maximum likelihood (ML) and restricted maximum likelihood (REML). The R statistical analysis package - function lme from the library nlme (R Development Core Team, 2008) was used for the generalized linear mixed-effectsmodelling. Minimization of the Akaike's Information Criterion was used for selecting the significant covariates (provided by the function stepAIC of $\mathrm{R}$ ), as well as for comparing homocedastic and heterocedastic models, and choosing between REML and ML fits.

\section{Results}

\subsection{Spatial heterogeneity at the reach scale}

Sediment, TOC and TN deposition, as well as related variables (TOC and TN concentration, particle-size separates) showed a high inter-site $-j=4-$ heterogeneity (Table 2 ). MP presented the highest sediment deposition rate. In turn, the remaining sites presented higher TOC and TN concentrations. Inter-site differences in TOC and TN deposition rates sites diminished when compared with sediment deposition, being the TOC and TN deposition the lowest at RF. With regard to particle-size separates, all fractions $<125 \mu \mathrm{m}$ presented similar inter-site differences than those observed for TOC and TN concentrations, with MP presenting the coarsest deposited sediment. However, particle-size composition did not significantly differ between examined sites regarding the $<250$ and $<500 \mu \mathrm{m}$ particle-size fractions.

The amount of deposited sediment was related with grain size only at RF (Table 3). At this site, particle-size separates $<125 \mu \mathrm{m}$ were negatively correlated with the amount of sediment deposited. In turn, those separates $>125 \mu \mathrm{m}$ were negatively correlated with the amount of TOC and TN deposited. Secondly, particle-size exerted a different influence over TOC and TN concentrations depending on the study site. At MP and RF, TOC and TN concentrations were positively correlated with particle-size separates $<125 \mu \mathrm{m}$. In turn, TOC and TN concentrations were negatively correlated with the $<500 \mu \mathrm{m}$ particle-size separate at MD, and positively with the $<4 \mu \mathrm{m}$ particle-size separate. At SF, the $<250$ and $<500 \mu \mathrm{m}$ particle-size separate was negatively correlated with TOC and TN content.
Spatial correlation was significant at distances lower than $0.94 \mathrm{~m}, 1.30 \mathrm{~m}$, and $1.32 \mathrm{~m}$ for Sediment, TOC and TN deposition, respectively. These results evidenced the need of a $1 \mathrm{~m}^{2}$ sample grid, at least, as the best structure capturing the spatial heterogeneity in the sediment deposition.

\subsection{Spatial heterogeneity at the reach, transect, row and plot scales}

Within the study reach, variability on sediment, TOC and TN deposition was unevenly distributed, as were for TOC and TN concentrations in the deposited sediment (Fig. 4). Moreover, variability of these variables (range) increased as their values (magnitude) increase. For Sediment, TOC and TN deposition, heterogeneity was in some cases (MP; MD) as high at the plot scale $\left(1 \mathrm{~m}^{2}\right)$ as it was for the row and transect scales. In turn, heterogeneity on TOC and TN concentration increased when increased sampling area. Within the examined areas, spatial heterogeneity on all examined variables was as high for the longitudinal gradient as it was for the perpendicular gradient (Fig. 4). Moreover, the study areas, the location of either a plot, transect or row determines its variability on depositional rates, as well as for TOC and TN concentrations. MP presented for depositional rates the highest site-scale variability for all the study sites. However, all other sites had the highest TOC and TN concentration variability.

\subsection{Generalized linear mixed-effects modelling}

Along the study reach, sediment deposited over the floodplain decreased with distance perpendicular to the main channel and distance to surface water inputs during the examined flood (Table 4). The random effects were large, as reflected by significant differences in the intercept parameter between sampling sites (Table 4). The GLME model for sediment accumulation was the most complex, and included heteroscesdasticity in the model errors, i.e., when grouping the data by the sampling site, resulting in differences in the residuals between sampling sites (Table 4). Fitting was obtained by maximum likelihood (ML). No significant relationship of particle-size composition over the quantity of deposited sediment was found. In addition, elevation did not present a significant relationship.

Longitudinal and perpendicular distances were significantly correlated with TOC and TN deposition rates. The $<250$ and $<500 \mu \mathrm{m}$ particle size-classes were also significantly correlated, presenting negative coefficients. In turn, the $<4$ and $<125 \mu \mathrm{m}$ fractions were significantly correlated but presenting positive coefficients. The random effects were smaller for TOC and TN deposition than for the sediment deposition, which was reflected by a smaller variance of between-sites model intercepts (Table 4). According to the AIC, homocedastic models (i.e. the magnitude of the residuals did not change between sampling sites) were better than 
Table 2. One-way ANOVA summary results for deposited sediment variables, grouped by study site. All variables presented significant differences except the $<250 \mu \mathrm{m}$ particle-size. Superscript letters $(\mathrm{a}, \mathrm{b}, \mathrm{c})$ within a row indicate the sub-groups formed after the applied posthoc comparisons (SNK or Tahmane Test, $p<0.05$ ).

\begin{tabular}{lllll}
\hline Mean \pm standar error & \multicolumn{5}{l}{} \\
\hline & MP $(n=41)$ & MD $(n=44)$ & SF $(n=44)$ & RF $(n=63)$ \\
\hline Sedrate $\left(\mathrm{Kg} \mathrm{m}^{-2}\right)$ & $13.49 \pm 2.19^{\mathrm{a}}$ & $5.51 \pm 0.53^{\mathrm{b}}$ & $4.18 \pm 0.27^{\mathrm{b}}$ & $4.15 \pm 0.38^{\mathrm{b}}$ \\
TOC $(\%)$ & $0.83 \pm 0.05^{\mathrm{a}}$ & $1.51 \pm 0.09^{\mathrm{b}}$ & $1.96 \pm 0.07^{\mathrm{c}}$ & $1.59 \pm 0.07^{\mathrm{b}}$ \\
$\mathrm{TN}(\%)$ & $0.10 \pm 0.01^{\mathrm{a}}$ & $0.18 \pm 0.01^{\mathrm{b}}$ & $0.22 \pm 0.01^{\mathrm{c}}$ & $0.18 \pm 0.01^{\mathrm{b}}$ \\
TOC $\left(\mathrm{g} \mathrm{C} \mathrm{m}^{-2}\right)$ & $112.49 \pm 19.52^{\mathrm{a}}$ & $77.26 \pm 7.91^{\mathrm{b}}$ & $78.93 \pm 4.08^{\mathrm{b}}$ & $56.13 \pm 4.36^{\mathrm{b}}$ \\
$\mathrm{TN}\left(\mathrm{g} \mathrm{N} \mathrm{m}^{-2}\right)$ & $11.56 \pm 1.67^{\mathrm{a}}$ & $8.79 \pm 0.83^{\mathrm{b}}$ & $9.10 \pm 0.46^{\mathrm{b}}$ & $6.36 \pm 0.44^{\mathrm{c}}$ \\
$<4 \mu \mathrm{m}(\%)$ & $2.83 \pm 0.16^{\mathrm{a}}$ & $4.27 \pm 0.22^{\mathrm{b}}$ & $5.53 \pm 0.26^{\mathrm{c}}$ & $4.19 \pm 0.22^{\mathrm{b}}$ \\
$<63 \mu \mathrm{m}(\%)$ & $24.01 \pm 1.43^{\mathrm{a}}$ & $32.67 \pm 1.43^{\mathrm{b}}$ & $40.44 \pm 1.39^{\mathrm{c}}$ & $31.11 \pm 1.24^{\mathrm{b}}$ \\
$<125 \mu \mathrm{m}(\%)$ & $43.75 \pm 2.20^{\mathrm{a}}$ & $50.37 \pm 1.78^{\mathrm{b}}$ & $57.62 \pm 1.45^{\mathrm{c}}$ & $48.85 \pm 1.30^{\mathrm{b}}$ \\
$<250 \mu \mathrm{m}(\%)$ & $74.49 \pm 1.84$ & $71.46 \pm 1.86$ & $74.57 \pm 1.39$ & $71.34 \pm 1.03$ \\
$<500 \mu \mathrm{m}(\%)$ & $92.88 \pm 0.69^{\mathrm{a}}$ & $88.90 \pm 1.27^{\mathrm{b}}$ & $88.96 \pm 0.90^{\mathrm{b}}$ & $88.56 \pm 0.76^{\mathrm{b}}$ \\
\hline
\end{tabular}

Table 3. Bivariate correlation between sediment particle-size, carbon and nitrogen concentration and deposition rates (sediment, TOC and TN). Data has been separated by study site: (a) RF, MP; (b) SF, MD. For an easier interpretation, correlations not related to the investigated aspects (see methods) are not displayed.

\begin{tabular}{|c|c|c|c|c|c|c|c|c|c|c|c|}
\hline & & \multicolumn{10}{|c|}{$\mathrm{RF}$} \\
\hline \multirow{12}{*}{$\hat{\Sigma}$} & & SEDrate & TOC & $\mathrm{TN}$ & TOCrate & TNrate & $4 \mu \mathrm{m}$ & $63 \mu \mathrm{m}$ & $125 \mu \mathrm{m}$ & $250 \mu \mathrm{m}$ & $500 \mu \mathrm{m}$ \\
\hline & SEDrate $(\mathrm{Kg} \mathrm{m}-2)$ & & - & - & - & - & $-0,45^{* *}$ & $-0,49^{* *}$ & $-0,43^{* *}$ & $-0,24$ & $-0,23$ \\
\hline & TOC (\%) & - & & - & - & - & $0,53^{* *}$ & $0,43^{* *}$ & $0,25^{*}$ & $-0,11$ & $-0,30^{*}$ \\
\hline & $\mathrm{TN}(\%)$ & - & - & & - & - & $0,61^{* *}$ & $0,52^{* *}$ & $0,34^{* *}$ & $-0,02$ & $-0,20$ \\
\hline & TOCrate ( $\mathrm{g} \mathrm{C} \mathrm{m-2)}$ & - & - & - & & - & $-0,15$ & $-0,22$ & $-0,25^{*}$ & $-0,35^{* *}$ & $-0,52^{* *}$ \\
\hline & TNrate $(\mathrm{g} \mathrm{N} \mathrm{m}-2)$ & - & - & - & - & & $-0,15$ & $-0,21$ & $-0,23$ & $-0,31^{*}$ & $-0,47^{* *}$ \\
\hline & $\%<4 \mu \mathrm{m}$ & $-0,13$ & $0,57^{* *}$ & $0,52^{* *}$ & 0,04 & 0,05 & & - & - & - & - \\
\hline & $\%<63 \mu \mathrm{m}$ & $-0,16$ & $0,55^{* *}$ & $0,48^{* *}$ & 0,01 & 0,02 & - & & & - & - \\
\hline & $\%<125 \mu \mathrm{m}$ & $-0,13$ & $0,55^{* *}$ & $0,43^{* *}$ & 0,04 & 0,05 & - & - & & - & - \\
\hline & $\%<250 \mu \mathrm{m}$ & 0,15 & $0,45^{* *}$ & 0,16 & 0,25 & 0,27 & - & - & - & & - \\
\hline & $\%<500 \mu \mathrm{m}$ & 0,27 & 0,21 & $-0,04$ & 0,23 & 0,27 & - & - & - & - & \\
\hline & & \multicolumn{10}{|c|}{ SF } \\
\hline \multirow{11}{*}{$\hat{\Sigma}$} & & SEDrate & TOC & $\mathrm{TN}$ & TOCrate & TNrate & $4 \mu \mathrm{m}$ & $63 \mu \mathrm{m}$ & $125 \mu \mathrm{m}$ & $250 \mu \mathrm{m}$ & $500 \mu \mathrm{m}$ \\
\hline & SEDrate $(\mathrm{Kg} \mathrm{m}-2)$ & & - & - & - & - & $-0,07$ & $-0,01$ & 0,10 & 0,23 & 0,25 \\
\hline & TOC (\%) & - & & - & - & - & $-0,07$ & $-0,24$ & $-0,38^{*}$ & $-0,54^{* *}$ & $-0,63^{* *}$ \\
\hline & $\mathrm{TN}(\%)$ & - & - & & - & - & 0,21 & 0,01 & $-0,19$ & $-0,39 * *$ & $-0,48^{* *}$ \\
\hline & TOCrate $(\mathrm{g} \mathrm{C} \mathrm{m}-2)^{2}$ & - & - & - & & - & $-0,03$ & $-0,09$ & $-0,09$ & $-0,06$ & $-0,09$ \\
\hline & TNrate (g N m-2) & - & - & - & - & & 0,11 & 0,06 & 0,05 & 0,06 & 0,06 \\
\hline & $\%<4 \mu \mathrm{m}$ & $-0,05$ & $0,33^{*}$ & $0,31^{*}$ & 0,17 & 0,22 & & - & - & - & - \\
\hline & $\%<63 \mu \mathrm{m}$ & $-0,06$ & 0,24 & 0,25 & 0,13 & 0,19 & - & & - & - & - \\
\hline & $\%<125 \mu \mathrm{m}$ & 0,06 & 0,07 & 0,07 & 0,17 & 0,23 & - & - & & - & - \\
\hline & $\%<250 \mu \mathrm{m}$ & 0,13 & $-0,19$ & $-0,19$ & 0,11 & 0,17 & - & - & - & & - \\
\hline & $\%<500 \mu \mathrm{m}$ & 0,13 & $-0,38^{*}$ & $-0,37^{*}$ & 0,00 & 0,06 & - & - & - & - & \\
\hline
\end{tabular}

* = Correlation is significant at the 0.05 level (2-tailed).

$* *=$ Correlation is significant at the 0.01 level (2-tailed). 


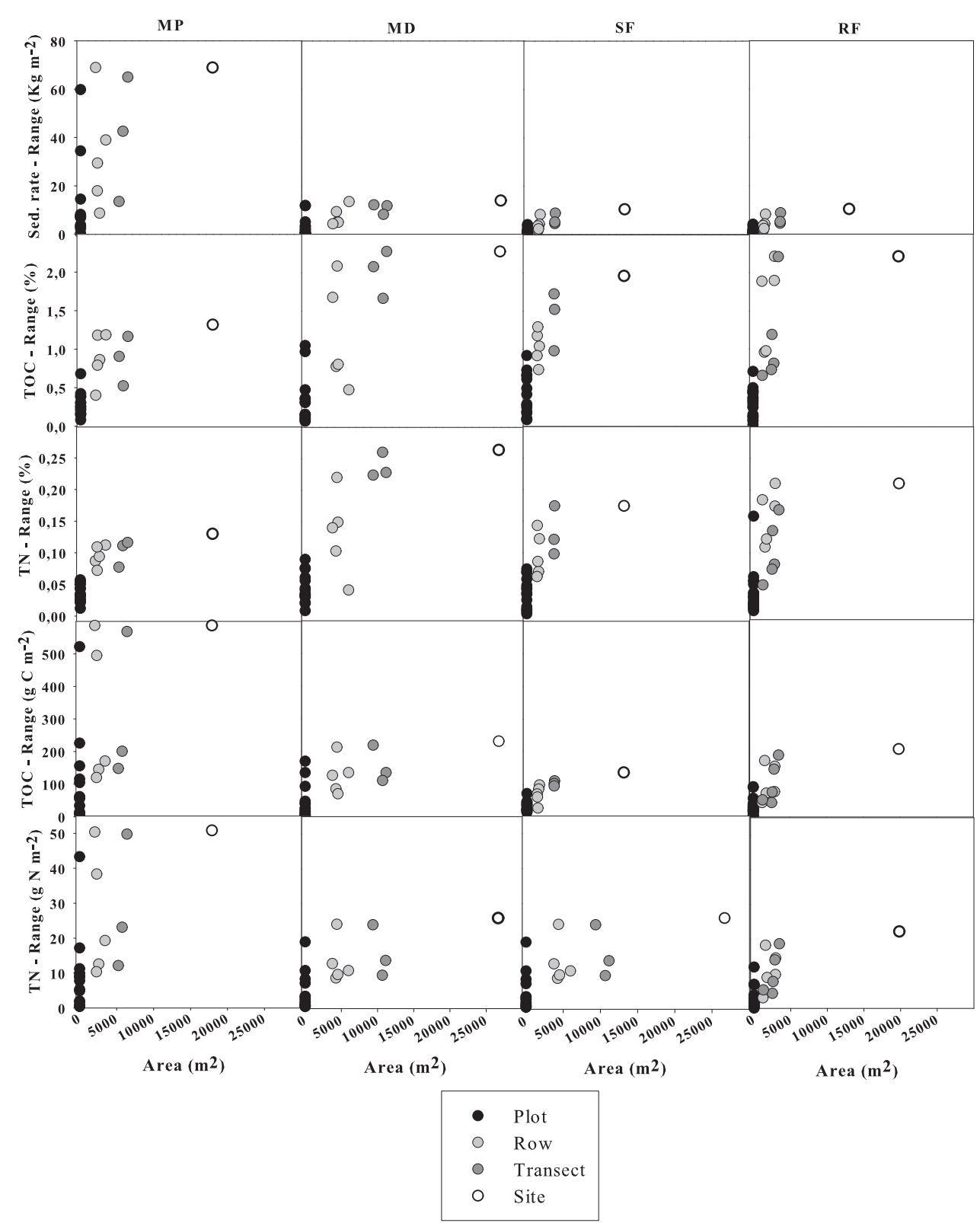

Fig. 4. TOC $\left(\%, \mathrm{~g} \mathrm{C} \mathrm{m}^{-2}\right)$, $\mathrm{TN}\left(\%, \mathrm{~g} \mathrm{~N} \mathrm{~m}^{-2}\right)$ and sedimentation rates $(\mathrm{kg} / \mathrm{m} 2)$ ranges for different spatial scales (plot, transect, row and site). See methods for details on area calculations.

heterocedastic models for TOC and TN deposition. AIC also indicated that RMLE was the best method to fit the TOC and TN heterocedastic models by using the AIC. Neither the $<63 \mu \mathrm{m}$ nor the elevation were estimated as significant and therefore not included in the model.

Coefficients to generate maps of predicted sediment rate, TOC and TN (Fig. 5) were obtained from the GLME models. As expected from the previous description, these maps reflect a high degree of spatial heterogeneity at the reach and site scales. As the fixed effects showed, the highest values of deposited sediment, TOC and TN in each sampling site were found close to the main channel and at the upstream end of the site. Differences between sites in the average sediment rate were large, the highest amounts occurring at MP and MD sites whereas lower values were predicted at SF and RF sites. For all sites, the predicted values reflect how sediment deposition decreases whit increasing distance from the main channel and upstream inputs, both of which are sediment sources.

Regarding TOC and TN deposition, the spatial patterns were similar for the sediment rate, although the perpendicular distance to the river had a stronger influence, according with the relation observed (Fig. 5). Also, the spatial models were a bit more complex than those of the sediment rate, 
Table 4. Summary of the results of the generalized linear mixed-effects models for sedimentation rate (SEDrate), Total Organic Carbon (TOCrate) and Total Nitrogen (TNrate): Goodness of fit statistic value (AIC); Fitting method: Maximum Likelihood (ML) or Restricted Maximum Likelihood (REML); Correlation parameters; Random effects for sampling site and model corresponding to the intercept and, in the case of heterocedasticity, in the residuals; Coefficients of the fixed effects: Coeff., Beta Coeff. (standarized coefficients) and p-values for the sedimentation rate (SEDrate), Total Organic Carbon (TOCrate) and Total Nitrogen (TNrate) models. Long. Dis. = Longitudinal distance; Perp. Dis. = Perpendicular distance (see methods for details).

\begin{tabular}{|c|c|c|c|c|c|c|c|c|c|}
\hline \multicolumn{10}{|c|}{ Response variables } \\
\hline & \multicolumn{3}{|c|}{ SEDrate } & \multicolumn{3}{|c|}{ TOCrate } & \multicolumn{3}{|c|}{ TNrate } \\
\hline AIC & \multicolumn{3}{|c|}{947.21} & \multicolumn{3}{|c|}{-488.72} & \multicolumn{3}{|c|}{-1424.18} \\
\hline Fitting method & \multicolumn{3}{|c|}{ ML } & \multicolumn{3}{|c|}{ REML } & \multicolumn{3}{|c|}{ REML } \\
\hline \multicolumn{10}{|c|}{ Correlation parameters } \\
\hline Range & \multirow{2}{*}{\multicolumn{3}{|c|}{$\begin{array}{l}1.183 \\
0.222\end{array}$}} & \multicolumn{3}{|c|}{0.897} & \multicolumn{3}{|c|}{0.898} \\
\hline Nugget & & & & \multicolumn{3}{|c|}{$2.87 \mathrm{E}-10$} & \multicolumn{3}{|c|}{$8.29 \mathrm{E}-09$} \\
\hline \multicolumn{10}{|c|}{ Random effects (per sampling site) } \\
\hline \multicolumn{10}{|l|}{ Intercept } \\
\hline MP & & 13.645 & & & 0.322 & & & 0.028 & \\
\hline MD & & 11.295 & & & 0.296 & & & 0.027 & \\
\hline $\mathrm{RF}$ & & 8.110 & & & 0.285 & & & 0.026 & \\
\hline SF & & 7.224 & & & 0.260 & & & 0.023 & \\
\hline \multicolumn{10}{|l|}{ Residual } \\
\hline MP & & 42.776 & & & & & & & \\
\hline MD & & 12.714 & & & 0.064 & & & 0.006 & \\
\hline $\mathrm{RF}$ & & 4.260 & & & & & & & \\
\hline SF & & 3.991 & & & & & & & \\
\hline \multicolumn{10}{|l|}{ Fixed effects } \\
\hline & Coeff. & Beta Coeff. & $\mathrm{p}$-value & Coeff. & Beta Coeff. & $\mathrm{p}$-value & Coeff. & Beta Coeff. & $\mathrm{p}$-value \\
\hline Long. Dis. & -0.01722 & -1.7184 & $0.0000^{*}$ & -0.00016 & -0.01622 & $0.0223^{*}$ & -0.00002 & -0.00184 & $0.0041^{*}$ \\
\hline Perp. Dis. & -0.05512 & -1.1337 & $0.0000^{*}$ & -0.00084 & -0.01722 & $0.0185^{*}$ & -0.00007 & -0.00146 & $0.0264^{*}$ \\
\hline$\%<4 \mu \mathrm{m}$ & - & - & - & 0.01310 & 0.02420 & $0.0152^{*}$ & 0.00108 & 0.00200 & $0.0251^{*}$ \\
\hline$\%<125 \mu \mathrm{m}$ & - & - & - & -0.00387 & -0.04833 & $0.0065^{*}$ & -0.00031 & -0.00393 & $0.0135^{*}$ \\
\hline$\%<250 \mu \mathrm{m}$ & - & - & - & 0.00547 & 0.05634 & $0.0037^{*}$ & 0.00048 & 0.00500 & $0.0041^{*}$ \\
\hline$\%<500 \mu \mathrm{m}$ & - & - & - & -0.00467 & -0.03104 & $0.0100^{*}$ & -0.00040 & -0.00269 & $0.0129^{*}$ \\
\hline
\end{tabular}

due to the existence in the model of covariates other than the distance to the river. Differences in the mean TOC and TN concentrations between were significantly lower than differences in sediment rate between sites.

\section{Discussion}

\subsection{Spatial heterogeneity at different scales}

Spatial heterogeneity at the reach scale $\left(10000-100000 \mathrm{~m}^{2}\right)$ influenced site-scale heterogeneity $\left(1000-10000 \mathrm{~m}^{2}\right)$ by limiting the variation range at the examined sites (Fig. 4). It occurred for the amount of sediment, TOC and TN deposited, as well as for TOC and TN concentrations. However, limitation of spatial heterogeneity at the plot scale $\left(1 \mathrm{~m}^{2}\right)$ by the site scale heterogeneity $\left(1000-10000 \mathrm{~m}^{2}\right)$ was not clear. Regarding the amount of sediment, TOC and TN deposited, the plot scale heterogeneity can be as high as it was for bigger spatial scales as row or transect. Regarding TOC and
TN concentrations, variability increase along with the spatial scale, and so with the extent of the examined area.

The relationship between the amount of sediment deposited and its particle-size composition varied when considering different spatial scales. Sediment deposition was negatively correlated at the reach scale with the proportion of the finest sediment fractions $(\%<4,63,125 \mu \mathrm{m} ; p<0.01$, $n=201)$, whereas positively correlated with the $\%<500 \mu \mathrm{m}$ particle-size separate $(p<0.01, n=201)$. This is similar to the reach-scale results of Steiger and Gurnell (2003). However, when analyzing the data at the site scale, we noted that this negative relationship at the reach scale was only found to exist at the RF site (Table 3), in agreement with results from Walling and He (1998) who found also no relationship between sediment deposition and grain size at the site scale. They highlighted the need to recognise that the suspended sediment transported by a river is commonly transported as aggregates rather than individual particles. In addition, convective transport processes could explain these 
trends (Asselman and Midlekoop, 1995). In turn, the reachscale relationships between TOC and TN concentrations on deposited sediments and particle size composition remained relatively stable when down-scaling to the site-scale. TOC and TN concentrations were positively correlated (Table 3 ) with the proportion of the finest sediment fraction at the reach scale $(\%<4,63,125 \mu \mathrm{m} ; p<0.01, n=201)$, whereas they were negatively correlated with the medium sand size fraction $(\%<500 \mu \mathrm{m} ; p<0.01, n=201)$. At the site scale, the importance of each fraction varied depending on the site. Positive relationships with the percentage of $<63 \mu \mathrm{m}$ particle-size separate have been previously reported (Walling and He, 1997; Steiger and Gurnell, 2003), although are provided for the remainder fractions in these papers.

At the reach scale, channel-floodplain geomorphology promoted heterogeneity on the amount and composition of sediment retained during the examined flood (Table 2). This trend has been previously observed in other studies dealing with contemporary sedimentation rates (Middlekoop and Van der Perk, 1998; Nicholas and Walling, 1998; Thonon et al., 2007). River-floodplain connectivity governs hydraulic patterns of overbank flows, and thus sedimentation patterns. Flooding took place later and was shorter at sites with the lower superficial connectivity thresholds (SF and RF in Tables 1 and 2), where sedimentation rates were the lowest. Moreover, a decrease on the amount of suspended sediment during the flood (Asselman and Middlekoop, 1998; Baborowski et al., 2007), which is higher at initial stages, could decrease the amount of sediment deposited at these sites. In turn, the proportion of the finest particle-size separates, i.e. $<125 \mu \mathrm{m}$ (fine sand) increased at those sites. Assuming homogeneity of suspended sediment composition within the study reach, it would result from a drastic decrease of flow velocity at main channel margins. As a result, the coarsest particles, which are normally transported by diffusive processes (Asselman and Middlekoop, 1995; Walling and He, 1998), are released before water enters the floodplain. Such phenomenon could also underlay results at MD, the high-connected side channel. At MD, the amount of sediment deposited was slightly higher than in low-connected sites. The location of MD in the concave bank of a river meander could reduce the quantity of sediment deposited by increasing erosion at certain flood stages (Steiger and Gurnell, 2003). At the other high-connected site, MP, extraordinary high sedimentation rates of coarse sediment were estimated. MP is characterized by a smooth topographic change at the border with the main channel.

At the site scale, complexity of local topography creates complex sedimentation patterns (Walling and He, 1998; Hupp et al., 2009). Spatial differences in sedimentation depend, at first, on the distance to water and sediment inputs (Table 4). Secondly, local topography attributes as relict channels create preferential flowpaths along which particles and aggregates are conveyed. Depletion of suspended sediment by sedimentation along preferential flow paths results
(Middelkoop and Van der Perk, 1998). At the examined sites, sediment, TOC and TN deposition varied along gradients which run parallel and perpendicular to the main channel (Fig. 5). Therefore, it is reasonable to assume that deposition from sediment entering the floodplain at the upstream area is as important as those entering adjacent areas to the main channel. Moreover, variability within these gradients can differ depending on the location of the area within the same study site. This implies that either suspended sediment concentrations decreased along flowpaths, or sediment is transported by convective processes further from the input point.

At the plot scale $\left(1 \mathrm{~m}^{2}\right)$, further research is required to elucidate factors promoting variability on the considered variables. Spatial heterogeneity may respond to heterogeneous vegetation structure within each plot, which modifies flow patterns and therefore result on differences on sediment deposition. Nicholas and Walling (1997) highlighted the need to include such effects on sedimentation modelling in order to improve its predictive ability at small spatial scales. Although factors promoting variability at the plot scale were not identified, our results indicate that the plot scale variability was smaller for TOC and TN concentrations that for the amount of sediment deposited (Fig. 4). This suggest that there is a certain degree of homogeneity in suspended sediment composition when a given floodplain area is flooded, and indicates that factors promoting heterogeneity at the plot scale mainly operate over the amount sediment which is deposited. In turn, factors promoting heterogeneity at larger spatial scales influenced TOC and TN concentrations. Results from the present study indicate that the amount of TOC and $\mathrm{TN}$ deposited depend on sediment quantity rather than in their TOC and TN contents (Table 2), in agreement with previous reports in this study reach (Cabezas et al., 2009). Consequently, studies dealing with TOC and TN retention by floodplain habitats should address influence of these hot spots. The crucial role of hot spots on TOC and TN retention has been previously highlighted for other biogeochemical processes implied in the TOC and TN turnover at riparian floodplains (McClain et al., 2003; Groffman et al., 2009).

\subsection{Linear mixed-effect models}

Using GLME models to evaluate sediment, TOC and TN deposition over riverine floodplains provided a valid framework to identify factors promoting heterogeneity at the reach scale by taking into account spatial heterogeneity at smaller spatial scales. GLME models allowed us to include different sampling sites in the same analysis, while discriminating between the variance explained by the fixed factors and the random variance depending on the local characteristics of the sites (sampling site, spatial auto-correlation). This allows for the generalization of study findings (Bolker and Brooks). In the current study, we could elucidate which variables were significant in controlling the spatial sedimentation patterns 


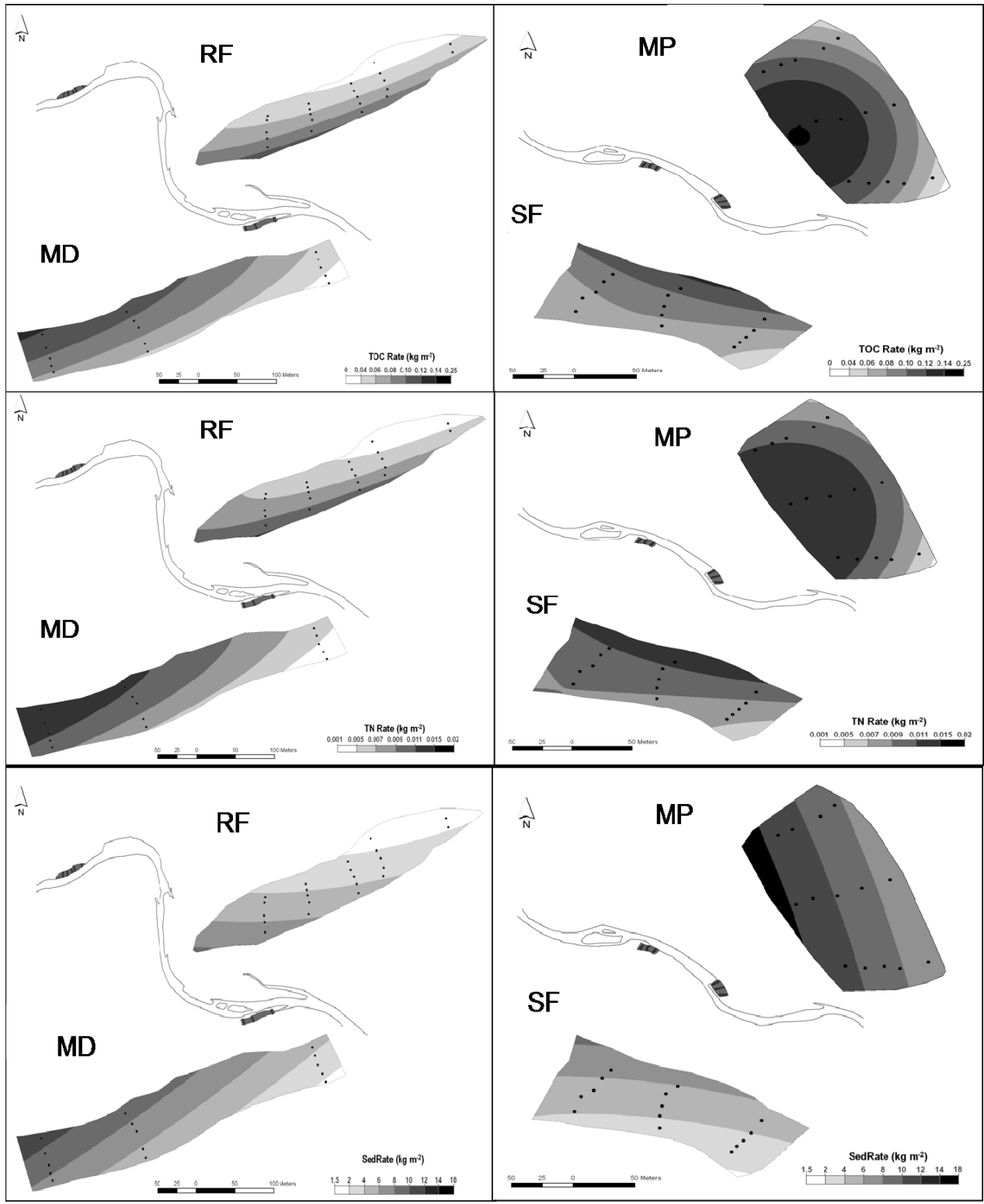

Fig. 5. Prediction maps sediment, TOC and TN deposition after the Generalized linear mixed-effects models.

of TOC, TN and deposition rate, independent of the site considered. The validity of our model at another Middle Ebro River reaches with similar geomorphological features is possible although must be investigated. However, a development of a new model which includes different-magnitude flood events is necessary to generalize our findings at larger temporal scales. Moreover, GLME handles small-scale heterogeneity by including all sampling units (pseudo-replicates) at each study plot. Previous studies (Steiger and Gurnell, 2003; Steiger et al., 2003) applied a lumped approach by averaging values of the clustered sampling units. According to our models, the amount of deposited sediment, TOC and $\mathrm{TN}$ decreases within the study reach with distance to superfi- cial water inputs (longitudinal and perpendicular distance in Table 4). The inverse relationship between elevation and sedimentation rate (Walling et al., 1996; Walling and He, 1998) could not be confirmed by this study. As Middelkoop and Asselman (1998) and Thonon et al. (2007b) found, this might be attributed to levees and other topographic features. Moreover, high flow velocities at low-lying areas can even reverse this trend at certain flood magnitudes (Asselman and Middlekoop, 1998). The inclusion of the particle size fractions in the TOC and TN deposition models reflects the influence that particle-size exerted on sediment composition at the four examined sites (Table 4). Assignation of model coefficients to the different particle-size classes respond to the best model 
goodness of fit and not to the previously described empirical relationships. Note that cumulative particle-size fractions were considered for this study.

Secondly, GLME models are able to predict Sediment, TOC and TN deposition at the reach scale taking into account spatial heterogeneity at smaller spatial scales. As a result, predicted deposition maps could be built for the four study sites included in the analyses (Fig. 5). To interpret predicted patterns, knowledge on site-specific features is required, as it was required by previous studies evaluating floodplain sedimentation by using different techniques than those performed in the current study (Middelkoop and Asselman, 1998; Steiger and Gurnell, 2003). However, GLME models are a useful tool when the scope of the study is to predict Sediment, TOC and TN deposition at heterogeneous river reaches rather than explaining spatial patterns at the site scale. At the study reach scale, homogeneity of spatial patterns was higher than expected for three of the four sites examined (Fig. 4). Flood magnitude and duration probably determined sediment deposition patterns at the examined sites. Also the position of study plots only in areas adjacent to the channel margin could influence the results. Future studies (either during different lower magnitude floods or positioning study plots in areas far to the main channel) are required to test the validity of our findings at spatio-temporal scales different than those considered in this study.

\section{Conclusions}

In the current paper, Sediment, TOC and TN deposition in one reach of the Middle Ebro River were evaluated by using GLME models. From this, we conclude:

1. As previously described for other study areas, channelfloodplain connectivity determines spatial heterogeneity on floodplain sedimentation at the reach scale, whereas micro-topography controls at the site scale.

2. Relationships between the amount of sediment deposited and its characteristics (particle size, TOC and $\mathrm{TN}$ concentration) vary when considering different spatial scales.

3. Sediment deposition variability at the plot scale $\left(1 \mathrm{~m}^{2}\right)$ can be as high as is for larger spatial scales (1000$10000 \mathrm{~m}^{2}$ ). This should be considered in future studies.

4. Factors determining heterogeneity at the plot scale exert a higher influence over the amount of sediment deposited than over TOC and TN concentrations.

5. By considering random effects, GLME can elucidate which variables were significant in controlling the spatial sedimentation patterns of TOC, TN and deposition rate, independent of the site considered. Thus, conclusions could be extrapolated with caution to different study sites.
6. GLME is a useful tool when the scope of the study is predicting Sediment, TOC and TN deposition at the reach scale while taking into account heterogeneity at smaller spatial scales.

Acknowledgements. Field works were funded by the Department of Environmental Science, Technology and University Government of Aragon (Research group E-61 on Ecological Restoration)- and MEC (CGL2005-07059). The Spanish Research Council (CSIC) granted Álvaro Cabezas through the I3P program (I3P-EPD2003-2), which was financed by European Social Funds (UE). Thanks are extended to Melchor Maestro for his help with the TN analyses. Research of M. Angulo-Martínez is supported by a JAE-Predoc Research Grant from the Spanish National Research Council (Consejo Superior de Investigaciones Científicas - CSIC).

Edited by: M. Gooseff

\section{References}

Asselman, N. E. M. and Middelkoop, H.: Floodplain Sedimentation - Quantities, Patterns and Processes, Earth. Surf. Proc. Land., 20, 481-499, 1995.

Asselman, N. E. M. and Middelkoop, H.: Temporal variability of contemporary floodplain sedimentation in the Rhine-Meuse Delta, the Netherlands, Earth. Surf. Proc. Land., 23, 595-609, 1998.

Baborowski, M., Buttner, O., Morgenstern, P., Kruger, F., Lobe, I., Rupp, H., and Von Tumpling, W. V.: Spatial and temporal variability of sediment deposition on artificial-lawn traps in a floodplain of the River Elbe, Environ. Manage., 48, 770-778, 2007.

Bolker, B. M., Brooks, M. E., Clark, C. J., Geange, S. W., Poulsen, J. R., Stevens, M. H. H., and White, J. S. S.: Generalized linear mixed models: a practical guide for ecology and evolution, Trends Ecol. Evol., 24, 127-135, 2009.

Buttner, O., Otte-Witte, K., Kruger, F., Meon, G., and Rode, M.: Numerical modelling of floodplain hydraulics and suspended sediment transport and deposition at the event scale in the middle river Elbe, Germany, Acta Hydroch. Hydrob., 34, 265-278, 2006.

Cabezas, A., Comin, F. A., Begueria, S., and Trabucchi, M.: Hydrologic and landscape changes in the Middle Ebro River (NE Spain): Implications for restoration and management, Hydrol. Earth Syst. Sci., 13, 273-284, 2009, http://www.hydrol-earth-syst-sci.net/13/273/2009/.

Cabezas, A., Comin, F. A., and Walling, D. E.: Changing patterns of organic carbon and nitrogen accretion on the middle Ebro floodplain (NE Spain), Ecol. Eng., 35, 1547-1558, 2009b.

Cabezas, A. and Comin, F. A.: Carbon and nitrogen accretion in the topsoil of the Middle Ebro River Floodplains (NE Spain): Implications for their ecological restoration, Ecol. Eng., 36, 640652, 2010.

Day, J. W., Ko, J. Y., Rybczyk, J., Sabins, D., Bean, R., Berthelot, G., Brantley, C., Cardoch, L., Conner, W., Day, J. N., Englande, A. J., Feagley, S., Hyfield, E., Lane, R., Lindsey, J., Mistich, J., Reyes, E., and Twilley, R.: The use of wetlands in the Mississippi Delta for wastewater assimilation: a review, Ocean Coast. Manage., 47, 671-691, 2004. 
Heegaard, E. and Nilsen, T.: Local linear mixed effect models Model specification and interpretation in a biological context, J. Agric. Biol. Envir. S., 12, 414-430, 2007.

Hupp, C. R.: Hydrology, geomorphology and vegetation of Coastal Plain rivers in the south-eastern USA, Hydrol. Process., 14, 2991-3010, 2000.

Hupp, C. R., Pierce, A. R., and Noe, G. B.: Floodplain geomorphic processes and environmental impacts of human alterations along coastal plain rivers, USA. Wetlands., 29, 413-429, 2009.

IPCC: Working Group III Report "Mitigation of Climate Change", Cambridge Univeristy Press, Cambridge, United Kingdom., 2007.

James, C. S.: Sediment transfer to overbank sections, J. Hydrol. Res., 23, 435-452, 1985.

Johnston, C. A.: Sediment and nutrient retention by freshwater wetlands - Effects on surface-water quality, Crit. Rev. Env. Contr., 21, 491-565, 1991.

Junk, W. J.: The flood pulse concept of large rivers: learning from the tropics, Arch. Hydrobiol., 3, 261-280, 1999.

Knosche, R.: Organic sediment nutrient concentrations and their relationship with the hydrological connectivity of floodplain waters (River Havel, NE Germany), Hydrobiologia, 560, 63-76, 2006.

Middelkoop, H. and Asselman, N. E. M.: Spatial variability of floodplain sedimentation at the event scale in the Rhine-Meuse delta, the Netherlands, Earth Surf. Proc. Land., 23, 561-573, 1998.

Middelkoop, H. and Van der Perk, M.: Modelling spatial patterns of overbank sedimentation on embanked floodplains, Geogr. Ann. A., 80A, 95-109, 1998.

Nicholas, A. P. and Walling, D. E.: Modelling flood hydraulics and overbank deposition on river floodplains, Earth Surf. Proc. Land., 22, 59-77, 1997.

Nicholas, A. P. and Walling, D. E.: Numerical modelling of floodplain hydraulics and suspended sediment transport and deposition, Hydrol. Proces., 12, 1339-1355, 1998.

Nicholas, A. P. and Mitchell, C. A.: Numerical simulation of overbank processes in topographically complex floodplain environments, Hydrol. Proces., 17, 727-746, 2003.

Noe, G. B. and Hupp, C. R.: Carbon, nitrogen, and phosphorus accumulation in floodplains of Atlantic Coastal Plain rivers, USA, Ecol. Appl., 15, 1178-1190, 2005.

Noe, G. B. and Hupp, C. R.: Retention of Riverine Sediment and Nutrient Loads by Coastal Plain Floodplains, Ecosystems, 12, 728-746, 2009.

Ollero, A.: Dinámica reciente del cauce de el Ebro en la Reserva Natural de los Galachos, Cuat. Geomor., 9, 85-93, 1995.

Owens, P. N., Batalla, R. J., Collins, A. J., Gomez, B., Hicks, D. M., Horowitz, A. J., Kondolf, G. M., Marden, M., Page, M. J., Peacock, D. H., Petticrew, E. L., Salomons, W., and Trustrum, N. A.: Fine-grained sediment in river systems: Environmental significance and management issues, River Res. Appl., 21, 693717, doi:10.1002/rra.878, 2005.

Piegay, H., Hupp, C. R., Citterio, A., Dufour, S., Moulin, B., and Walling, D. E.: Spatial and temporal variability in sedimentation rates associated with cutoff channel infill deposits: Ain River, France, Water Resour. Res., 44, W05420, doi:10.1029/2006WR005260, 2008.

Pierce, A. R. and King, S. L.: Spatial dynamics of overbank sedimentation in floodplain systems, Geomorphology, 100, 256-268,
2008.

Pinheiro, J. C. and Bates, D. M.: Mixed-Effects Models in S and S-PLUS, Springer, New York, 530 pp., 2000.

Pizzuto, J. E.: Sediment diffusion during overbank flows, Sedimentology, 34, 301-317, 1987.

Preiner, S., Drozdowski, I., Schagerl, M., Schiemer, F., and Hein, T.: The significance of side-arm connectivity for carbon dynamics of the River Danube, Austria, Freshwater Biol., 53, 238-252, 2008.

Robertson, A. I., Bunn, S. E., Boon, P. I., and Walker, K. F.: Sources, sinks and transformations of organic carbon in Australian floodplain rivers, Mar. Freshwater Res., 50, 813-829, 1999.

Sakamoto, Y., Ishiguro, M., and Kitagawa, G.: Akaike Information Criterion Statistics, Reidel, Dordrecht, Holland., 1986.

Steiger, J. and Gurnell, A. M.: Spatial hydrogeomorphological influences on sediment and nutrient deposition in riparian zones: observations from the Garonne River, France, Geomorphology, 49, 1-23, 2003.

Steiger, J., Gurnell, A. M., and Goodson, J. M.: Quantifying and characterizing contemporary riparian sedimentation, River Res. Appl., 19, 335-352, 2003.

Stewart, M. D., Bates, P. D., Price, D. A., and Burt, T. P.: Modelling the spatial variability in floodplain soil contamination during flood events improve chemical mass balance estimates, in: Hihg-Resolution Modelling in Hydrology and Geomorphology, edited by: Bates, P. D. and Lane, S. D., Wiley, Chichester, 239261, 1999.

$\mathrm{R}$ development core team, R: A language and Environment for Statistical Computing, Foundation fro Statistical Computing, (http: //www.R-project.org), Vienna, Austria. 2008.

Thonon, I., de Jong, K., van der Perk, M., and Middelkoop, H.: Modelling floodplain sedimentation using particle tracking, Hydrol. Process., 21, 1402-1412, 2007.

Thonon, I., Middelkoop, H., and van der Perk, M.: The influence of floodplain morphology and river works on spatial patterns of overbank deposition, Neth. J. Geosci., 86, 63-75, 2007 b.

Thoms, M. C.: Floodplain-river ecosystems: lateral connections and the implications of human interference, Geomorphology, 56, 335-349, 2003.

Tockner, K., Pennetzdorfer, D., Reiner, N., Schiemer, F., and Ward, J. V.: Hydrological connectivity, and the exchange of organic matter and nutrients in a dynamic river-floodplain system (Danube, Austria), Freshwater Biol., 41, 521-535, 1999.

Tockner, K., Malard, F., and Ward, J. V.: An extension of the flood pulse concept, Hydrol. Process., 14, 2861-2883, 2000.

Verhoeven, J. T. A., Arheimer, B., Yin, C. Q., and Hefting, M. M.: Regional and global concerns over wetlands and water quality, Trends Ecol. Evol., 21, 96-103, 2006.

Walling, D. E., He, Q., and Nicholas, A. P.: Floodplains as Suspended Sediment Sinks, in: Floodplain Processes, edited by: Anderson, G. M., Walling, D. E., and Bates, P. D., Wiley, Chichester, 399-440, 1996.

Walling, D. E. and He, Q.: Investigating spatial patterns of overbank sedimentation on river floodplains, Water Air Soil Poll., 99, 920, 1997.

Walling, D. E., Owens, P. N., and Leeks, G. J. L.: The characteristics of overbank deposits associated with a major flood event in the catchment of the River Ouse, Yorkshire, UK, Catena, 31, 
53-75, 1997.

Walling, D. E. and He, Q.: The spatial variability of overbank sedimentation on river floodplains, Geomorphology, 24, 209-223, 1998.

Walling, D. E. and Owens, P. N.: The role of overbank floodplain sedimentation in catchment contaminant budgets, Hydrobiologia, 494, 83-91, 2003.
Walling, D. E.: Quantifying the fine sediment budgets of river basins., Proceedings Irish National Hydrology Seminar, 9-20, 2004.

Wentworth, C. K.: A scale of grade and class terms for clastic sediments. J. Geol., 30, 377-350, 1922.

Witherington, B., Kubilis, P., Brost, B., and Meylan, A.: Decreasing annual nest counts in a globally important loggerhead sea turtle population, Ecol. Appl., 19, 30-54, 2009. 